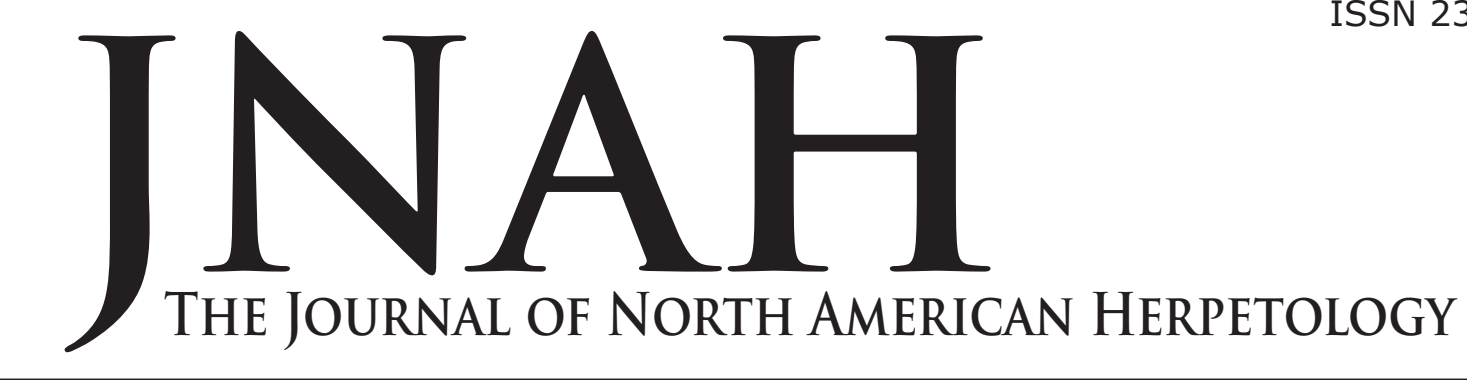

ISSN 2333-0694

Volume 2017(1): 5-10

29 March 2017

jnah.cnah.org

\title{
AGGRESSIVE BEHAVIORS AND THEIR EFFECT ON RESOURCE USE BY MALE LITTLE BROWN SKINKS, SCINCELLA LATERALIS
}

\author{
LAURA MYERS ${ }^{1}$ AND MARK PAULISSEN ${ }^{2}$ \\ Department of Curriculum and Instruction, Northeastern State University, Tahlequah, Oklahoma 74464 \\ and Department of Natural Sciences, Northeastern State University, Tahlequah, Oklahoma 74464 \\ 1 Present address: Grand View Middle School, 15481 North Jarvis Rd, Tahlequah, OK 74464 - Imyers@ \\ grandview.k12.ok.us \\ 2 Corresponding author: paulisse@nsuok.edu
}

\begin{abstract}
The aggressive behaviors of adult male Little Brown Skinks, Scincella lateralis, and their effects on access to an important resource (a single retreat) were the subject of a study consisting of 10 laboratory trials in which the behavioral interactions between a pair of individuals was recorded. Analysis of these interactions made it possible to identify a dominant and a subordinate male in each trial; the male with the greater bulk was dominant in 9 of the 10 trials. Aggressive behaviors recorded include lunging, chasing, and biting; the dominant male performed lunging significantly more often than the subordinate male and was the only individual to exhibit chasing. The most common behavior recorded was avoidance which was shown almost exclusively by the subordinate male. Both dominant and subordinate males exhibited tail twitching which we hypothesize to be a sign of agitation. The two males spent significantly more time on opposite sides of the observation chamber than on the same side and almost never occupied the single retreat simultaneously because the subordinate male repeatedly moved to avoid the dominant male. The implications of these results on spacing patterns and resource use of Scincella lateralis in the wild are discussed.
\end{abstract}

INTRODUCTION

Territoriality refers to the active defense of an area against intruders that allows the resident to monopolize the territory's resources (Vitt and Caldwell 2014). Among lizards, territoriality is common in species within the Iguania (sensu Sites et al. 2011), including many North American species in the families Phrynosomatidae, Crotaphytidae, Iguanidae, and Dactyloidae (Stamps 1977; Martins 1994; Vitt and Caldwell 2014). Many of these species use visual displays such as "head bobs", "push-ups" or dewlap extensions as well as overt aggression to defend their territories (reviewed in Carpenter and Ferguson 1977). The conspicuousness and visual displays of North American Iguanians has stimulated a wealth of research that has shaped herpetology's understanding of aggressive behavior and resource use in lizards.

By contrast, the world's most speciose lizard family, the Scincidae, has received far less attention. Reviews of lizard spacing patterns suggested skinks generally are not territorial, but may defend small specific sites such as retreats or basking sites (Stamps 1977; Martins 1994). Specific site defense is probably the ancestral condition in skinks (Martins 1994; Vitt and Caldwell 2014), though a few species exhibit true territoriality (e.g., Jennings and Thompson 1999; Stapley and Keogh 2004). Aggressive behaviors of various types have been documented in many species of skinks (Torr and Shine 1996; Jennings and Thompson 1999; Stapley 2006), including North American species in the genus Plestiodon (formerly Eumeces) (Fitch 1954; Perrill 1980; Cooper and Vitt 1987). But little is known about how such behaviors affect use of resources by the contestants.

Studies of another North American skink, Scincella lateralis (formerly Lygosoma laterale), commonly known as the Little Brown Skink, have shown it also displays aggression towards conspecifics, though detailed descriptions of aggressive behaviors have not been published. Early anecdotal accounts noted Little Brown Skinks will fight with each other when caged together (Lewis 1951; Brooks 1967). In a more recent study, Akin (1998) paired Little Brown Skinks in an experimental chamber and observed their interactions after a pre-trial acclimation period. He noted that the skinks showed aggression (defined as biting) and avoidance (defined as time spent on the side of the experimental chamber where a skink was acclimated), but provided no other descriptions of skink behaviors. Even less well understood is the effects of aggressive behaviors on skink resource use. Stamps (1977) suggested Little Brown Skinks may 
Table 1. Description of behaviors exhibited by male little brown skinks (Scincella lateralis) when they came within one body length of each other during 60 minute experimental trials in the observation chamber.

\begin{tabular}{ll}
\hline Behavior & Description \\
\hline Lunge & $\begin{array}{l}\text { One lizard jerks rapidly about one body length toward the other lizard (which typically responded } \\
\text { by fleeing). Usually exhibited by the dominant male. }\end{array}$ \\
Chase & Similar to the lunge except the aggressor lizard pursues the fleeing lizard for at least $10 \mathrm{~cm}$, of- \\
ten from one side of the observation chamber to the other. Exhibited exclusively by the dominant \\
male.
\end{tabular}

show home range defense (i.e. territoriality) because females have non-overlapping home ranges (Brooks 1967). However, male home ranges, which are much larger than those of females, do overlap suggesting an absence of territoriality in male Little Brown Skinks. Furthermore, Fitch and von Achen (1977) provided evidence that Little Brown Skinks home ranges were poorly defined and that skinks spent most of their time inactive in their hiding places from which they made only brief forays for feeding and other activities. Because of the Little Brown Skink's low activity, combined with its completely terrestrial habit, it seems unlikely any intruder into a skink's home range would be detected making defense of a home range and exclusive access to resources within the defended area impossible. With one exception, no study of Little Brown Skinks has addressed the defense and monopolization of a specific site or resource against other lizards. The exception, Akin (1998), showed subordinate males consumed as many termites from a food dish located in the center of an experimental chamber as dominant males. This suggests that aggressive behaviors exhibited by male skinks toward each other may not lead to specific site defense or resource monopolization.

The foregoing demonstrates substantial gaps in the understanding of Little Brown Skink aggression and its impact on this species' ecology. The purpose of this study is to describe the aggressive behavioral interactions of adult male Little Brown Skinks recorded in laboratory dyadic encounter trials and to determine if these interactions influence space use and/or resource monopolization.

\section{MATERIALS AND METHODS}

Study Animals and Captive Maintenance - Twenty adult male Little Brown Skinks were caught by hand from an oak-hickory forest at Sparrowhawk Primitive Area, Cherokee County, Oklahoma. All lizards were caught in June or July 2012, 2013, or 2014. Each lizard's snout-vent length (SVL) was measured in $\mathrm{mm}$ with a plastic ruler; mass was measured to the nearest $0.1 \mathrm{~g}$ using a triplebeam balance. Only skinks greater than $40 \mathrm{~mm}$ SVL were used. Skinks were housed individually in 30.5 X $14.0 \mathrm{X}$
$7.6 \mathrm{~cm}$ high clear plastic boxes that were provided with a paper towel lining the floor and a cardboard retreat consisting of a one-quarter arc of a toilet paper roll tube. Water was always available in a small water dish; 8-10 small mealworms from a laboratory culture were offered daily unless mealworms from the previous day had not been eaten. Each box was heated with a $60 \mathrm{~W}$ heat lamp connected to a timer set to a $12 \mathrm{hr}: 12 \mathrm{hr}$ light:dark photoperiod cycle. Testing was completed within 10 days after a skink was caught; each skink was tested only once after which it was released near its point of capture. Experimental Design - A 10-gallon glass aquarium ( $50.2 \times 26.4 \times 30.5 \mathrm{~cm}$ high) was set up as an observation chamber. The back and two sides of the chamber were covered with dark green posterboard; the front of the chamber was left uncovered to allow filming of lizard behaviors. The floor of the chamber was covered by a $2 \mathrm{~cm}$ thick layer of fine garden soil mixed with sand to approximate natural soil conditions. The substrate was turned over and well mixed between trials to disperse residual odors. The observation chamber received light from a pair of $60 \mathrm{~W}$ heat lamps suspended $20 \mathrm{~cm}$ above the floor of the chamber. The lamps were connected to a timer set to the same photoperiod cycle as the individual lizard cages.

Each behavioral trial involved two male skinks and began with an acclimation phase. The observation chamber was divided into two equal sized halves by a partition of cardboard covered with vinyl (to prevent skinks from climbing the partition). Each side received heat and light from one of the $60 \mathrm{~W}$ heat lamps and was provided with a food dish containing mealworms, a water dish, and a cardboard retreat similar to the retreats in the skinks' home cages. A single male skink was placed in each of the two sides of the divided observation chamber. The two skinks differed in SVL by $1-5 \mathrm{~mm}$ (mean $\pm \mathrm{SE}=2.6$ $+0.06 \mathrm{~mm}$ ) in 8 of the 10 trials. In the ninth trial, the two skinks differed in SVL by $12 \mathrm{~mm}$; in the tenth trial, the two skinks had the same SVL but differed in mass by $0.2 \mathrm{~g}$. Thus it was possible to distinguish between the two males as one "large" and one "small" in all ten trials. The skinks were left undisturbed for 48 hours save for brief interruptions to resupply food or water. During 
Table 2. Mean \pm SE number of times dominant and subordinate male Little Brown Skinks (Scincella lateralis) performed various behaviors during 60 minute observation periods in the observation chamber. The P-value of paired t-tests comparing the dominant to the subordinate males is shown, and "*" indicates statistical significance $(P<0.05)$; $N=10$ trials. See Table 1 for a description of the behaviors.

\begin{tabular}{llll}
\hline & Dominant & Subordinate & $P$-Value of t-test \\
\hline Lunge & $1.6 \pm 0.45$ & $0.3 \pm 0.21$ & $0.045^{*}$ \\
Chase & $3.0 \pm 1.54$ & 0.0 & 0.082 \\
Bite & $3.5 \pm 2.31$ & $0.7 \pm 0.50$ & 0.274 \\
Avoid/Flee & $0.2 \pm 0.13$ & $26.0 \pm 6.83$ & $0.004 *$ \\
Tail Twitch & $1.4 \pm 0.48$ & $0.9 \pm 0.32$ & 0.177 \\
\hline
\end{tabular}

this acclimation phase, the skinks were free to move throughout their side of the divided chamber, including entering and leaving the retreat, but they could not interact with the skink on the other side of the partition. This acclimation phase allowed each skink to become familiar with its "home" side of the observation chamber.

After the 48 hour acclimation phase, the experimental trial to record skink behavioral interactions was begun. The partition, all food and water dishes, and the two home side retreats were removed and a new, clean cardboard retreat, large enough for both skinks to fit under, was placed in the center of the now undivided observation chamber. Skinks were free to move anywhere within their home side or to move to the opposite side of the observation chamber. Skink behaviors were recorded for the next 60 minutes using a SONY REV280 analog (tape) recorder placed in front of the observation chamber. There were no people present to ensure skink behaviors were not influenced by human distractions. After the 60 min trials, the skinks were returned to their home cages where they remained until they were released.

Data Collection and Analysis - Tapes were analyzed to describe and quantify behaviors that occurred during the 60 min trials. As the two skinks moved about the chamber, they frequently came to within one body length of each other creating the potential for a behavioral interaction. Each time this occurred, the behaviors of both skinks were recorded. A description of the behaviors observed is given in Table 1 . We used the number of times the skinks performed avoidance/flight behavior to determine

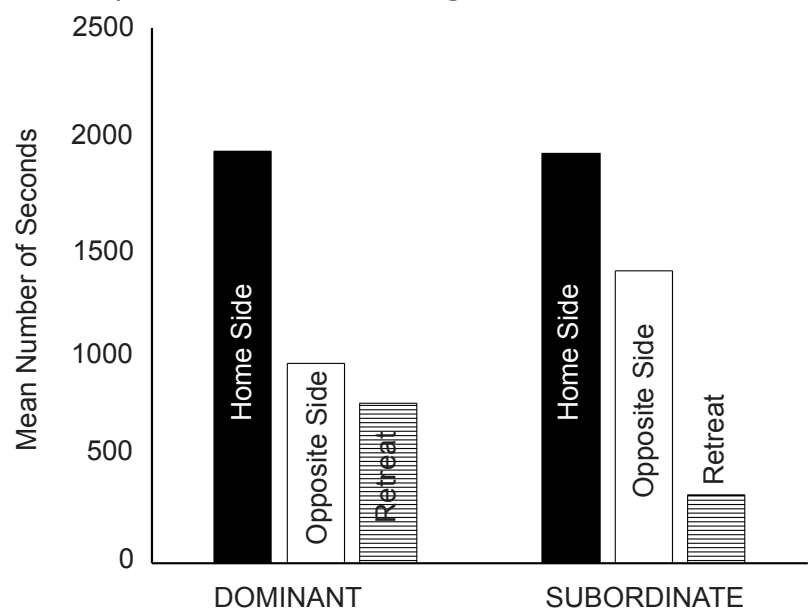

Figure 1. Mean number of seconds dominant and subordinate male Little Brown Skinks (Scincella lateralis) spent on their home side of the observation chamber, the opposite side of the observation chamber, and under the single retreat in the center of the observation chamber. Though the dominant male spent more time under the retreat than the subordinate male, the difference was not significant (paired t-test: $\mathrm{t}=1.759, \mathrm{df}=9$, $P=0.112$ ). which of the two skinks in the trial was subordinate; the other skink was designated as dominant (see Results).

In addition to behaviors, we also measured the following for each lizard: how much time it spent on its "home" side of the observation chamber, how much time it spent on the opposite side of the chamber, and how much time it spent in the single retreat in the center. We also recorded how much time the two skinks spent on the same side of the observation chamber as well as how much time they spent on opposite sides. These variables were measured to determine if the dominance relationship established had any effect on space use by either the dominant or the subordinate skink. However, these two variables could only be quantified when both skinks were outside the retreat; this left intervals of time when one or both skinks was under the retreat unquantified. To account for the time when skinks used the retreat, we derived two additional variables: "Together" defined as the amount of time the two skinks were on the same side of the observation chamber plus the amount of time they were under the retreat together; "Apart" defined as the amount of time the two skinks were on opposite sides of the chamber plus the amount of time one skink was under the retreat while the other was not. Statistical comparison of the means of all variables were made using paired t-tests.

\section{RESULTS}

After the partition was removed at the beginning of a trial, the two skinks remained stationary for up to 5 min, after which one or both skinks began to move around the observation chamber. Typically within 1-2 min, the two skinks came to within one body length of each other and a behavioral interaction occurred (though occasionally the two skinks moved past each other without exhibiting any obvious behaviors). No displays or interactive behaviors were ever observed when the two skinks were more than one body length apart. The behaviors exhibited during the early minutes of a trial were commonly aggressive and included biting, chasing, and lunging by one skink and avoidance/flight by the other (Table 1). In one trial, both skinks bit each other's heads simultaneously, locked jaws, and rolled around violently for $2 \mathrm{sec}$ before separating. As trials progressed, however, overtly aggressive behaviors were seen less frequently so that the most common behavior exhibited overall was avoidance. This behavior was recorded more often than all other behaviors combined (Table 2) and frequently occurred without the other skink displaying an obvious aggressive behavior. The lizard performing avoidance behavior more often in a trial was identified as the subordinate male; the other was therefore identified as the dominant male. There was never any ambiguity in these designations as the subordinate male repeatedly exhibited avoidance/flight behavior when it came to within one body length of the dominant male after the 
first few minutes of the trial.

Dominant males performed lunging significantly more often than subordinate males (Table 2). Similarly, chasing was performed exclusively by the dominant male, though the low frequency of chases meant the difference between dominant and subordinate males narrowly failed to reach statistical significance (Table 2). The dominant male also bit the subordinate male more often than the subordinate male bit the dominant male, but this trend also failed to reach statistical significance (Table 2) because subordinate males sometimes bit dominant males in retaliation or as part of mutually aggressive interactions that occasionally occurred at the beginning of trials. Tail twitching was performed by both dominant and subordinate males at about equal frequency.

The mean \pm SE SVL of the 20 skinks used in this study was $45.4 \pm 0.739 \mathrm{~mm}$; mean \pm SE mass was $1.8 \pm$ $0.081 \mathrm{~g}$. The skink with the greater SVL and mass was dominant in 7 of the 10 trials. In two of the other three trials, the two skinks were equal in mass but the one with the shorter SVL was dominant. Thus, in 9 of the 10 trials, the skink with the greater bulk was the dominant male (Binomial test: $P=0.0107$ ).

Both the dominant and the subordinate males spent more time on their home side of the observation chamber than on the opposite side (Figure 1). The dominant male spent more time under the retreat than the subordinate male, but the difference was not statistically significant (paired t-test: $\mathrm{t}=1.759, \mathrm{df}=9, P=0.112$; Figure 1 ).

When both skinks were outside the retreat, they spent significantly more time on opposite sides of the observation chamber (mean $\pm \mathrm{SE}=1834.4 \pm 263.8$ ) than on the same side (mean \pm SE $=701.5 \pm 386.3$; paired t-test: $\mathrm{t}=-3.498, \mathrm{df}=9, P=0.007)$. This was because when the two males came to within one body length of each other, the subordinate male nearly always avoided the dominant male, often by fleeing to the opposite side of the chamber. Because the time one or both males used the retreat was not included in this calculation, we computed the statistics "Together" and "Apart" to account for the times that one or both lizards used the retreat (see Material and Methods). The results were similar: the two males spent significantly more time "Apart" (mean \pm SE $=2889.7 \pm 381.3)$ than "Together" $($ mean \pm SE $=709.8 \pm 383.6$; paired $t$-test: $t=-9.002$, $\mathrm{df}=9, P<0.001)$. The two males very seldom used the retreat simultaneously (mean \pm SE number of sec both males under retreat $=8.3 \pm 4.3)$. This was because if the dominant male was under the retreat, the subordinate male never entered it, and if the subordinate male was under the retreat and the dominant male entered, the subordinate male ran out from under the retreat within seconds.

\section{DISCUSSION}

The behaviors adult male Little Brown Skinks displayed during their behavioral interactions are ones commonly described in studies of skink behavior. For example, chasing was performed exclusively by dominant males and lunging was exhibited significantly more often by dominant males than by subordinate males. Many other species of skinks assert dominance by chasing their rivals (e.g. Zwickel and Allison 1986; Torr and Shine 1996; Jennings and Thompson 1999; Sanchez-Hernandez et al. 2012). Dominant male Little Brown Skinks also bit their opponents much more often than they were bitten by their opponents, though the difference fails to reach statistical significance because the subordinate skinks sometimes bit back (Table 2). Biting is also a common behavior exhibited by skinks; it has been documented previously in Little Brown Skinks (Akin 1998) and many other skink species (Cooper and Vitt 1987; Torr and Shine 1996; Jennings and Thompson 1999; Stapley 2006; Fenner and Bull 2010; Sanchez-Hernandez et al. 2012). Though chases, lunges, and biting are the most dramatic aggressive behaviors exhibited by adult male Little Brown Skinks, by far the most common behavior exhibited was avoidance of the dominant male by the subordinate male. Once the dominance relationship was established after an initial period of chases, lunges, and bites, the subordinate male regularly avoided the dominant male even if the latter showed no obvious aggressive behavior. The typical pattern was for both skinks to move about the observation chamber, pausing occasionally to bask or to investigate something, and then to resume moving. If the dominant male was stationary when the subordinate male approached, the subordinate male darted around the dominant male, often to the opposite side of the observation chamber. If the subordinate male was stationary when the dominant male approached, the subordinate male typically darted off in the opposite direction. If both males were moving when they approached each other, the subordinate male either abruptly changed direction and ran off or darted around the dominant male; in either case, the subordinate male often ran to the side of the observation chamber opposite the side occupied by the dominant male. This behavior is again commonly seen in skinks (Perrill 1980; Zwickel and Allison 1986; Cooper and Vitt 1987; Whittier and Martin 1992; Sanchez-Hernandez et al. 2012), including Little Brown Skinks (Akin 1998). The behaviors chase/lunge, bite, and avoid are probably common to skinks in general and play an important role in establishing and maintaining dominance relationships. One behavior we recorded that was not listed in the behavioral inventory of Little Brown Skinks published by Akin (1998) was tail twitching. This behavior was displayed by both dominant and subordinate males, sometimes simultaneously as they faced each other or stood parallel to each other. It was also sometimes displayed by a stationary skink, either the dominant or the subordinate male, as the other skink approached. Several studies have documented similar tail movements by skinks in the presence of conspecifics, but the intensities and functions of these movements appear to vary among species. For example, Perrill (1980) described a slow "tail wag" displayed by juvenile Plestiodon (formerly Eumeces) inexpectatus towards adults that he interpreted as a submissive behavior, and a rapid "tail vibration" display that he interpreted as dominance. Sanchez-Hernandez et al. (2012) described "tail undulation" by Chalcides viridanus; it was usually displayed in response to another skinks's display, occurred before biting or after being bitten, and was usually displayed by subordinate individuals. Studies by Langkilde et al. (2003; 2004) described three levels of "tail wave" exhibited by Carlia jarnoldae, noting that tail waving is rarely performed by solitary skinks, and may be a signal by resident males directed towards intruders and/or a signal to a predator. Torr and Shine (1994) described "tail lashing" and "tail twitching" by Lampropholis guichenoti and noted these behaviors were displayed by both dominants and subordinates. Though Torr and Shine (1996) suggested a social signal function as well as a possible antipredator function for tail movements, they also offered that such 
tail movements may simply be a sign of "agitation". In the present study, we did not distinguish among the different levels of tail twitching, but the fact that this behavior was displayed frequently by both dominant and subordinate male Little Brown Skinks suggests it is not an aggressive or submissive behavior in this species. Additionally, the absence of any predatory threat in our study suggests tail twitching is not an antipredatory behavior in Little Brown Skinks. Lacking any obvious functional significance, we favor the hypothesis that tail twitching is a sign of agitation in Little Brown Skinks rather than a social signal, though detailed studies to specifically address the issue are needed.

In most lizard species, body size is a major determinant of dominance relationships. Skinks are no exception as it is generally true that larger males tend to be dominant over smaller ones (Zwickel and Allison 1986; Cooper and Vitt 1987; Whittier and Martin 1992; Torr and Shine 1996), though other factors such as coloration may also be important (Stapley 2006). In the present study, the bulkier male (i.e. the one with the greater SVL and mass or the one with the greater mass/SVL ratio), was dominant in 9 of 10 trials, suggesting that large size confers an advantage in establishing dominance in male Little Brown Skinks. Perhaps male Little Brown Skinks assess some correlate of muscle size, such as jaw width or body girth, to parse dominance relationships. When two males lock jaws and fight by rolling around on the ground it may be the individual that is physically stronger wins and emerges as the dominant lizard.

Any time the two males came close to each other, the subordinate avoided the dominant, often by fleeing from one side of the chamber to the other. This accounts for why the two skinks spent significantly more time on opposite sides of the observation chamber than on the same side and why they spent so little time "Together" (defined as simultaneously on the same side of the chamber or simultaneously under the retreat). The only important resource available to the two males was the retreat. The amount of time that the dominant and subordinate males used the retreat simultaneously was less than $0.25 \%$ of total observation time; this was because if the dominant male was under the retreat, the subordinate male did not enter, and if the subordinate male was under the retreat and the dominant male entered, the subordinate male quickly left. This suggests the dominant male had exclusive access to the observation chamber's only meaningful resource at any time he chose to use it. This contrasts with the study by Akin (1998) which showed that the dominant and subordinate males consumed the same number of termites during the experimental trial indicating a lack of exclusive access to an important resource. The contradiction between the present study and Akin (1998) is explained by comparing the resources available in the two studies. In Akin (1998), 30 termites were confined to a petri dish in the center of the observation chamber where either lizard could access them and feed as long as the other lizard was not nearby. Since male Little Brown Skinks moved around the chamber during the behavioral trials, there were probably several occasions when the dominant male was far enough away from the central termite dish that the subordinate male could feed from it, making it impossible for the dominant male to monopolize this resource. In the present study, the retreat in the center of the observation chamber could be monopolized by one lizard if it simply occupied the retreat and subsequently prevented the other lizard from entering, or if one skink chased the other skink out from under the retreat when it entered. The dominant male consistently acted just this way and so was able to acquire exclusive access to the retreat.

The results of this study are relevant to understanding spacing patterns and resource use of male Little Brown Skinks in the wild. We consider it unlikely that male Little Brown Skinks defend fixed territories in nature. True territoriality requires that the resident aggressively responds, via a display or overt aggression, to any conspecific that intrudes within the boundaries of its territory even if the intruder is not physically close to the resident. In our study, male Little Brown Skinks did not exhibit displays or any interactive behaviors toward each other if the skinks were more than $10 \mathrm{~cm}$ apart; they only interacted when they were within one body length of each other. Indeed, the small size and terrestrial habit of Little Brown Skinks make it unlikely that a male could detect another male entering its territory unless the resident just happened to be at the exact point where the intruder entered. It is more likely that male Little Brown Skinks carry out their daily activities within an undefended home range within which there may be several retreats (Fitch and von Achen 1977). Home ranges of males overlap, sometimes extensively (Brooks 1967) presumably because male Little Brown Skinks don't interact with each other unless they happen to come to within a few centimeters of each other. Occasions when two males do come into contact are marked by aggressive behaviors (chase, lunge, bite) by one malethe dominant one-leading to avoidance behavior by the other male. If an encounter occurred in or near a retreat, the dominant male would claim exclusive access to that retreat at least for the time during which the dominant lizard occupies that retreat. This spacing pattern is basically "Specific Site Defense" described by Stamps (1977) and hypothesized to be the ancestral condition in the family Scincidae and related families (Martins 1994; Vitt and Caldwell 2014).

This study shows that male Little Brown Skinks aggressively interact each other when they come close together, that these interactions may affect space use (in that the subordinate male always moves away from the dominant male), and that subordinate males are not allowed to share a retreat with a dominant male. Though these results add to our understanding of a common North American skink species, they raise many additional questions meriting study. For example, if a subordinate male Little Brown Skink encounters a recently used but presently unoccupied retreat of a dominant male, would it enter that retreat? Duvall et al. (1980) showed male Little Brown Skinks avoid odors of other males; but that study used an olfactometer to test skink reactions to airborne odors and did not consider dominance relationships. Study of subordinate male response to substrate odors of dominant males at retreats would be necessary to address this question. Also of interest would be a study of aggressive interactions between adult female Little Brown Skinks. Previous work has suggested that adult female Little Brown Skinks aggressively interact with each other (Akin 1998; L. Myers and M. Paulissen, unpublished data), and that smaller females typically show avoidance of larger ones (Akin 1998). The fact that home ranges of adult female Little Brown Skinks usually do not overlap whereas home ranges of adult males do (Brooks 1967) suggests there might be differences between the sexes in how aggressive interactions determine spacing patterns. Finally, nothing 
is known about the aggressive interactions that might occur between neonate Little Brown Skinks. Studies of several Iguanian species have suggested that aggressive interactions between neonates or juveniles are of critical importance to a lizard's long-term survival chances (Fox et al 1981; Stamps and Krishnan 1998). That nothing is known about the aggressive interactions between neonate skinks, or their potential to influence survival, highlights how much work is needed to fill in the gaps in herpetology's knowledge of skink ecology. A combination of controlled laboratory studies coupled with detailed field studies of both sexes and all age-classes will have to be conducted before these gaps can finally be filled in.

Acknowledgements - Part of this research was completed by L. Myers in partial fulfillment of the requirements for graduating with Honors; we thank Karen Carey and the Northeastern State University (NSU) Honors Program for their assistance. Support for this project was provided by a NSU Faculty Research Committee grant awarded to M. Paulissen. We thank Brian Becker for providing assistance in capturing and caring for the lizards. The research protocols were approved by the NSU Animal Welfare Committee (IACUC \#2010-02). Lizards were collected under the authority of a Scientific Collecting Permits (\#5265, \#5530, and \#5903) granted to M. Paulissen by the Oklahoma Department of Wildlife Conservation.

\section{LITERATURE CITED}

Akin, J. A. 1998. Intra- and inter-sexual aggression in the ground skink (Scincella lateralis). Canadian Journal of Zoology 76:87-93.

Brooks, G. R. 1967. Population ecology of the ground skink, Lygosoma laterale (Say). Ecological Monographs 37:71-87.

Carpenter, C. C., and G. W. Ferguson. 1977. Variation and evolution of stereotyped behavior in reptiles.

Pp. 335-554, In: Gans, C., and T. W. Tinkle. Biology of the Reptilia Volume 7: Ecology and Behaviour A. Academic Press, New York, NY.

Cooper, W. E., and L. J. Vitt. 1987. Deferred agonistic behavior in a long-lived scincid lizard Eumeces laticeps. Oecologia 72:321-326.

Duvall, D., R. Herskowitz, and J. Trupiano-Duvall. 1980. Responses of five-lined skinks (Eumeces fasciatus) and ground skinks (Scincella lateralis) to conspecific and interspecific chemical cues. Journal of Herpetology 14:121-127.

Fenner, A. L., and C. M. Bull. 2010. Central-place foraging in a burrow-dwelling skink: aggressive responses to conspecific models in pygmy bluetongued lizards. Journal of Zoology 283:454-51.

Fitch, H. S. 1954. Life history and ecology of the fivelined skink, Eumeces fasciatus. University of Kansas Publications of the Museum of Natural History 8:1156.

Fitch, H. S., and P. L. von Achen. 1977. Spatial relationships and seasonality in the skinks Eumeces fasciatus and Scincella laterale in northeastern Kansas. Herpetologica 33:303-313.

Fox, S. F., E. Rose, and R. Myers. 1981. Dominance and the acquisition of superior home ranges in the lizard Uta stansburiana. Ecology 62:888-893.

Jennings, W. B., and G. G. Thompson. 1999. Territorial behavior in the Australian scincid lizard Ctenotus fallens. Herpetologica 55:352-361.

Langkilde, T., L. Schwarzkopf, and R. Alford. 2003. An ethogram for adult male rainbow skinks, Carlia jarnoldae. Herpetological Journal 13:141-148.

Langkilde, T., L. Schwarzkopf, and R. Alford. 2004. The function of tail displays in male rainbow skinks, Carlia jarnoldae. Journal of Herpetology 37:328-335.

Lewis, T. H. 1951. The biology of Leiolopisma laterale (Say). American Midland Naturalist 45:232-240.

Martins, E. P. 1994. Phylogenetic perspectives on the evolution of lizard territoriality. Pp. 115-144, In: Vitt, L. J., and E. R. Pianka. Lizard Ecology: Historical and Experimental Perspectives. Princeton University Press, Princeton, NJ.

Perrill, S. A. 1980. Social communication in Eumeces inexpectatus. Journal of Herpetology 14:129-135.

Sanchez-Hernandez, P, M. P. Ramirez-Pinilla, and M. Molina-Borja. 2012. Agonistic and courtship behaviour patterns in the skink Chalcides viridanus (Fam. Scincidae) from Tenerife. Acta Ethologica 15:65-71.

Sites, J. W., T. W. Reeder, and J. J. Wiens. 2011. Phylogenetic insights on evolutionary novelties in lizards and snakes: sex, birth, bodies, niches, and venom. Annual Review of Ecology, Evolution, and Systematics 42:227-244.

Stamps, J. A. 1977. Social behavior and spacing patterns in lizards. Pp. 265-334, In: Gans, C., and T. W. Tinkle. Biology of the Reptilia Volume 7: Ecology and Behaviour A. Academic Press, New York, NY.

Stamps, J. A., and V. V. Krishnan. 1998. Territory acquisition in lizards IV. Obtaining high status and exclusive home ranges. Animal Behaviour 55:461472.

Stapley, J. 2006. Individual variation in preferred body temperature covaries with social behaviours and colour in male lizards. Journal of Thermal Biology 31:362-369.

Stapley, J., and J. S. Keogh. 2004. Exploratory and antipredator behaviours differ between territorial and nonterritorial male lizards. Animal Behaviour 68:841846.

Torr, G. A., and R. Shine. 1994. An ethogram for the small scincid lizard Lampropholis guichenoti. AmphibiaReptilia 15:21-34.

Torr, G. A., and R. Shine. 1996. Patterns of dominance in the small scincid lizard Lampropholis guichenoti. Journal of Herpetology 30:230-237.

Vitt, L. J., and J. P. Caldwell. 2014. Herpetology: An Introductory Biology of Amphibians and Reptiles, Fourth Edition. Academic Press, New York, NY.

Whittier, J. M., and J. Martin. 1992. Aspects of social behaviour and dominance in male rainbow skinks, Carlia rostralis. Australian Journal of Zoology 40:7379.

Zwickel, F. W., and A. Allison. 1986. Inter- and intrasexual interactions in a New Guinea skink, Emoia physicae. Canadian Journal of Zoology 64:752-755. 